\title{
Klar auf Erfolgskurs!
}

Deutsche Zahnärzte verwenden immer häufiger Universal-Adhäsive. Diese gestatten, die Füllungstherapie mit nur noch 1 einzigen Adhäsiv durchzuführen, welches für sämtliche Ätztechniken geeignet ist: die Self-Etch-Technik, die Etch \& RinseTechnik sowie das selektive Schmelzätzen. Dadurch werden die Arbeitsabläufe in der zahnärztlichen Praxis weiter vereinfacht und vor allem sicherer. Aktuelle Marktzahlen bestätigen den Trend zu Universal-Adhäsiven.

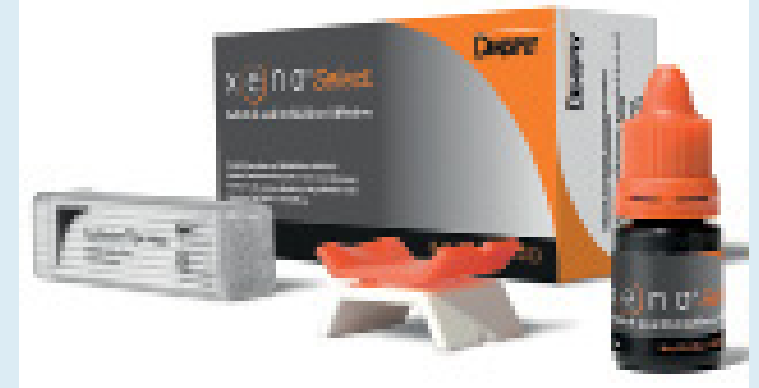

Besonders fällt hier das erst seit Januar 2014 erhältliche Xeno Select (Dentsply) auf: Nach nur 12 Monaten nimmt es innerhalb der Gruppe der 7 führenden Universal-Adhäsive einen Marktanteil von 17\% ein. Die Qualität des Produkts bestätigen viele Anwender sowie mehrere materialwissenschaftliche und klinische Studien: Das Material ist robust gegenüber unterschiedlichen Feuchtegraden des Dentins und bietet eine zuverlässige Haftleistung, sogar bei übertrocknetem Dentin. Postoperative Sensibilitäten nach seinem Einsatz sind nahezu unbekannt.

Weitere Informationen zu Xeno Select können jetzt unter der kostenlosen Dentsply Service-Line für Deutschland 0 80 00/7350 00 sowie im Internet unter www.dentsply. de angefordert werden.

Nach einer Pressemitteilung der Dentsply DeTrey GmbH, Konstanzr 